themselves, however, the dominating faunal features of the intermediate Jacksonian ought to have carried conviction, or nearly that, to the mind of any unprejudiced paleontologist. The Zeuglodontidae, represented (as generally considered) by the two genera Zeuglodon and Squalodon, are thus far positively known (in their earliest forms) only from late eocene or miocene (and oligocene?) deposits; and the only species of the former other than the American forms, and those obtained by Schweinfurth from Birket-el-Keroun (and recently referred by Dames to the eocene or oligocene horizon), is a member of the same group of deposits (the Bartonian) which in England correspond in position with the Jackson beds; i.e., overlie the Parisian (equal Claibornian). In that which relates to the oligocene (Orbitoide, Nummulite) rock of the peninsula of Florida, whose existence appears to give $\mathrm{Dr}$. Meyer a considerable amount of anxiety, and which would better suit the requirements of the new theory were it cretaceous, our author need entertain no doubts: the rock is there, and has recently been found in several other localities which were not known at the time the mapping for my book was executed. No amount of chastising of Orbitoides will efface the testimony which it has unguardedly left behind.

I fully agree with Professor Hilgard as to the value of tracing derivative relationships between the species of the different formations, - a field of inquiry which I entered some years ago, but from which I have thus far drawn but barren fruit. In such inquiry it is necessary, however, to know the relative positions of the different deposits with which one is dealing, and not to proceed, as Dr. Meyer has done, from top to bottom, believing that top was bottom, and bottom top. Some curious evolutionary results might arise from this novel method of procedure.

For the rest, I need only reiterate my warning to geologists and paleontologists against the acceptance of the vagaries which are set forth in the two articles before us. Having given attentive study to the fossils from the region in question for a period extending over six years, and with the types of by far the greater number of species that have ever been described from the formation under my eyes and under my charge, I can say that those portions of Dr. Meyer's papers which relates to systematic paleontology are of about equal value with the geological, aud clearly show that the author has not yet even found time to identify the numerous species which he is discussing. Pseudo-science of the kind to which we are here treated should be exposed. ANGELo HeILPRIN.

Academy of natural sciences, Philadelphia, July 20.

\section{The etymology of 'ginkgo.'}

Mr. Lester F. Ward, in a note to his paper on the ginkgo-tree (Science, v. 495, June 19, 1885), says, "The orthography of this word ['ginkgo'] is not settled. Linné wrote 'ginkgo,' as did also, apparently, Kaempfer before him ('Amoenitat. exotic.,' 1712), and as all botanists since have done, and do still; but nearly all lexicographer's reverse the consonants, and write ' gingko.' . . . In the supplement to Webster's dictionary the word is said to signify 'silver fruit;' and it would seem that the etymology ought to determine the orthography."

The first use of the word ginkgo occurs in Kaempfer's 'Amoenitates exoticae', p. 811, where he says,

“梠銀 Ginkgo, vel gín an, vulgo itsjò. Arbor nucifera folio adiantino." And then he adds a page of detailed description, and a page of figures of the leaves and fruit. He gives the two Chinese characters that are still used for the fruit in Japan: they are pronounced by two different methods, according to two provincial pronunciations brought to Japan long ago, and corrupted there, - either gink zyyoo (not the common English oo, but each o long, or as in 'oolite;' and the $g$ as in 'give,' of course), or, much more commonly, ginnan; and they mean 'silver apricot,' or 'silver almond.'

It is plain that Kaempfer's ginkgo was a misprint

for ginkjoo; since the second character (香) is also

given by him on p. 798 for the apricot, and transliterated kjoo, - a very reasonable way to write it, with the German sound of $j$, and the long $o$ doubled, as actually pronounced. Undoubtedly, the last syllable of the word was written in the same way at p. 811; but, in printing, it became kgo, and the error has been sacredly perpetuated until the present time.

The word ginnan (the first $n$ is doubled in pronunciation) is likewise misprinted, on p. 812, 'ginnaù.'

Instead of ginkiyoo, or ginnan, the name of the fruit, the tree is called in Japan ichoo (two long $o$ 's, as before, not the English oo, but the ch as in English), and that is what Kaempfer writes itsjò.

Thunberg ('Flora japonica,' 1784, p. 358), probably guided by his own ear, in amendment of Kaempfer, writes the name ginko, which represents a third less common Japanese pronunciation of the second syllable, koo, with two long $o$ 's; and he speaks of the great size of the tree, comparing the thickness of the trunk to oaks. Possibly the evident errors of the Linnean name in spelling, pronunciation, and meaning (signifying the fruit rather than the tree, though Dr. Williams's dictionary says the same name is in China given also to the tree; and it is in Japan, too, sometimes given to the fruit-bearing sex of it), may be considered strong arguments in favor of the name 'Salisburia;' or, perhaps better, in favor of 'Thunberg's reform of the orthography - if that be not treading on altogether too holy ground.

Kaempfer pointed fut the resemblance of the leaf to Adiantum, not only on p. 811 , but again in the detailed description on the next page.

My copy of Kaempfer has an old manuscript note, as follows, - "1753. See this plant in Mr. James Gordon's garden at Mile End, London," - showing that the tree was very early introduced in Europe.

The tree sometimes grows to a very large size, and there was one about five feet in diameter in my garden at Yedo, on high ground; but damp soil is said to be its preference. The juice of the thick pulp outside the nut is very astringent, and is used in making a somewhat waterproof, tough paper, and a preservative black wash for fences and buildings. The meat of the nut is cooked and eaten.

Northampton, Mass.

BenJ. Smith Lyman.

\section{THE RECENT LAND-SLIDE IN THE WHITE MOUNTAINS.}

Between Jefferson and the well-known Fabyan House, in the White Mountains of New Hampshire, is an oblong elevation of thirty-six hundred feet above the sea, known as Cherry Mountain. It is about seven miles in length 